\title{
Effect of overexpression of Oct4 and Sox2 genes on the biological and oncological characteristics of gastric cancer cells
}

This article was published in the following Dove Press journal: OncoTargets and Therapy

\author{
Borong Chen ${ }^{1, *}$ \\ Zhipeng Zhu',* \\ Lulu $\mathrm{Li}^{1}{ }^{1, *}$ \\ Weipeng $\mathrm{Ye}^{2}$ \\ Junjie Zeng' \\ Jin Gao' \\ Shengjie Wang' \\ Liang Zhang' \\ Zhengjie Huang ${ }^{1,2}$ \\ 'Department of Gastrointestinal Surgery, \\ Xiamen Cancer Hospital, The First \\ Affiliated Hospital of Xiamen University, \\ Xiamen, Fujian 361003, People's Republic \\ of China; ${ }^{2}$ Department of Clinical \\ Medicine, Fujian Medical University, \\ Fuzhou, Fujian 350004, People's Republic \\ of China \\ *These authors contributed equally to \\ this work
}

Correspondence: Zhengjie Huang Department of Gastrointestinal Surgery, Xiamen Cancer Hospital, The First Affiliated Hospital of Xiamen University, 55 Zhen Hai Road, Si Ming District,

Xiamen, Fujian Province 361003, People's Republic of China

Tel +865922139280

Fax +86592 2137368

Email huangzhengjie@xmu.edu.cn
Objective: Using the gastric cancer cell line SGC7901, we constructed a cell line that overexpressed octamer-binding protein 4 (Oct4) and SRY-box 2 (Sox2) to explore the stem cell oncological and biological characteristics of these cells and to elucidate the mechanisms of Oct4 and Sox2 in cancer.

Methods: A lentiviral vector containing the Sox 2 gene was constructed and transfected into a gastric cancer cell line overexpressing Oct4 (SGC7901-Oct4) to obtain a stably transfected cell line (SGC7901-Oct4-Sox2). Oct4 and Sox2 expression was detected by RT-PCR and Western blotting. The proliferation, drug resistance, migration, and invasion abilities of the cells were assessed using in vitro (3-(4,5-dimethylthiazol-2-yl)-5-(3-carboxymethoxyphenyl)-2-(4-sulfophenyl)-2H-tetrazolium), drug resistance, scratch-wound migration, transwell migration, transwell invasion, and spherical clone formation assays, and their tumorigenic ability was assessed using a tumor formation experiment in mice.

Results: Compared with the control group, the expression of Oct4, Sox2, CD44, and E-cadherin was significantly higher in the group that overexpressed Oct4 and Sox2, while the expression of c-Myc and Klf4 did not significantly change. The proliferation, drug resistance, migration, and invasion abilities were significantly enhanced in the overexpression group, and the tumorigenic ability in mice was also significantly enhanced, with significantly increased tumor size and weight.

Conclusion: The proliferation, drug resistance, migration, invasion, and tumorigenic abilities of SGC7901 cells overexpressing Oct4 and Sox 2 were significantly improved. Oct4 and Sox 2 play important roles in the proliferation, migration, invasion, and tumorigenicity of gastric cancer cells, and the two genes may be synergistic to a certain degree.

Keywords: stomach cancer SGC7901, Oct4, Sox2, stem cells

\section{Introduction}

Gastric cancer is one of the most common malignant tumors in China, and it is also the most common tumor in the digestive system. The morbidity and mortality rates of gastric cancer in China are the highest rates for all malignant tumors, and gastric cancer is difficult to diagnose early, has poor prognosis, and has high rates of recurrence and metastasis. Studies have shown that the abnormal expression of stem cell genes plays an important role in the occurrence, development, recurrence, and metastasis of gastric cancer. So far, studies have demonstrated abnormal expression of the stem cell gene SRY-box2 (Sox2) in a variety of malignant tumor tissues, including esophageal cancer, ${ }^{1}$ gallbladder cancer, ${ }^{2}$ gastric cancer, 
pancreatic cancer, ovarian cancer, ${ }^{3}$ colorectal cancer, ${ }^{4}$ and prostate cancer, and Sox 2 expression is proportional to the rate of occurrences of distant metastasis. The transcription factor octamer-binding 4 protein (Oct4) plays an important role in maintaining the self-renewal of embryonic stem cells, and Oct4 also participates in the regulation of multidirectional differentiation in embryonic development. ${ }^{5} \mathrm{At}$ present, many studies have reported abnormal expression of Oct4 in many malignant tumor tissues or cell lines, ${ }^{6,7}$ suggesting that Oct4 not only plays a role in stem cell growth, but it may also be involved in the occurrence and development of tumor tissue.

By introducing the stem cell gene Sox 2 into lentiviral vector-infected gastric cancer cells overexpressing the stem cell gene Oct4, we produced gastric cancer cells overexpressing Sox 2 and Oct4 and then assessed their proliferation, drug resistance, invasion, and tumorigenicity abilities. We studied the change of the cells' biological characteristics to seek evidence for the hypothesis that Oct4 and Sox 2 may be key factors for treating gastric cancer.

\section{Materials and methods}

\section{Ethics statement}

This study and all experimental protocols were approved by the Animal Care and Use Committee of Xiamen University and carried out in accordance with the guidelines of the Animal Care and Use Committee of Xiamen University.

\section{Materials}

\section{Drugs and reagents}

We obtained Roswell Park Memorial Institute (RPMI) 1640 medium, TRizol total RNA extraction reagent, and diethyl pyrocarbonate (DEPC) water (TIANGEN BIOTECH, Beijing, China); Trans2K Plus II DNA Marker and FBS (Qiagen, Dusseldorf, Germany); goat anti-mouse secondary antibody, Oct4 antibody, Sox2 antibody, CD44 antibody, E-cadherin antibody, and $\beta$-actin antibody (Abcam, Cambridge, USA); PrimeScript RT Enzyme Mix I (x 200) and SYBR Green 820A (Takara, Tokyo, Japan); and Oct4 primer, Sox2 primer, CD44 primer, E-cadherin primer, KLF4 primer, c-Myc primer, B27 additive, human epidermal growth factor (EGF), and human basic fibroblast growth factor (bFGF; Invitrogen, Carlsbad, USA).

\section{Cell line}

$293 \mathrm{~T}$ cells were provided by Bestway Biological Technology (Shenzhen, China). The gastric cancer cell line SGC7901 was provided by the School of Life Sciences, Xiamen University, which as approved by the Ethics Committee of Xiamen University. Stably transfected SGC7901-ZPP cells (which were used as the negative control group) and stably transfected SGC7901-Oct4 cells (which were used to create the SGC7901-Oct4-Sox2 group) were stored and supplied by the Tumor Center of the First Affiliated Hospital of Xiamen University, as approved by the Ethics Committee of Xiamen University. The SGC7901, SGC7901-ZPP, and SGC7901-Oct4 cell lines were all gastric cancer cell lines.

\section{Plasmids}

The lentiviral plasmid pLVX-hSox2-ZsGreen-puro (which encodes a bright green fluorescent protein) and the lentiviral overexpression plasmid pLVX-Neo-IRES-tdTomato (which encodes a bright red fluorescent protein) were purchased from (Shen zhen, China) Bestway Technology Co., Lid.

\section{Animals}

A total of 21 randomly selected healthy NOD/SCID male mice (8-12 weeks, $20 \pm 4 \mathrm{~g}$ ), were provided by Xiamen University Laboratory Animal Center. Before the experiment, the mice were raised at $19-22^{\circ} \mathrm{C}$ with $40-50 \%$ relative humidity and a noise level $<50 \mathrm{~dB}$, and the mass fraction of ammonia was $20 \times 10^{-6}$.

\section{In vitro experiments \\ Cell culture}

The cell lines SGC7901-ZPP and SGC7901 adhere to the wall of the culture dish when growing. They were cultured in RPMI 1640 medium supplemented with 10\% FBS and $1 \%$ streptomycin mixture at $37^{\circ} \mathrm{C}$ in a humidified atmosphere of $5 \% \mathrm{CO}_{2}$. The nutrient solution was changed every 2-3 days. When the cells spread to $90 \%$ of the culture dish, $0.25 \%$ trypsin was added for digestion, and serial subculturing was conducted.

\section{Identification, amplification, and extraction of} recombinant lentiviral expression plasmids encoding Sox2

The pLVX-Neo-Sox2-IRES-tdTomato plasmid was digested and identified using EcoRI and NotI enzymes. A 954-bp band, representing the correct recombinant clone, was identified. Sequencing using the primer CGCAAATGGGCGGTAGGCGTG (CMV-F) indicated that the plasmid sequence was completely consistent with the sequence in GenBank. The correct plasmid sequence 
was transformed into E. coli JM109 competent cells for amplification. The plasmids were then extracted from the E. coli cells using a small plasmid extraction kit (Beijing TransGenBiotech Co., Ltd.). The relative absorbance, in terms of the ratio of the OD at $260 \mathrm{~nm}$ to the OD at 280 $\mathrm{nm}$, was measured by ultraviolet spectrophotometry to calculate the concentration and purity of the DNA, which was preserved at $20^{\circ} \mathrm{C}$.

\section{Lentivirus packaging and viral titer determination}

293 T cells were digested with $0.25 \%$ trypsin and cultured until they spread over $70 \%$ of the petri dish. At about $3 \mathrm{hrs}$ before transfection, the culture medium was replaced with medium containing no antibiotics (DMEM+10\% FBS). A mixture of pLVX-Neo-Sox2-IRES-tdTomato, vector, HET Buffer B, and ddH2O was added to the $10-\mathrm{cm}$ cell culture plate to be cultured in an incubator at $37^{\circ} \mathrm{C}$ with $5 \%$ $\mathrm{CO}_{2}$. After $15 \mathrm{hrs}$, the culture medium was replaced with $8 \mathrm{~mL}$ complete medium (DMEM $+10 \% \mathrm{FBS}+1 \%$ penicillin). After $24 \mathrm{hrs}$, the supernatant was collected and stored in a $4^{\circ} \mathrm{C}$, and $8 \mathrm{~mL}$ of the above medium was added to continue the culture. After $48 \mathrm{hrs}$, the supernatant was collected and mixed with the supernatant collected in the previous step. After centrifugation ( $5 \mathrm{mins}, 1,000 \mathrm{rpm}$ ), the supernatant was filtered using a $0.45-\mu \mathrm{m}$ polyvinylidene fluoride (PVDF) filter to remove the cell debris. After 2 hrs of high-speed centrifugation $\left(4^{\circ} \mathrm{C}, 50,000 \mathrm{~g}\right)$, the supernatant was discarded and the lentiviral sediment was dried. DMEM (without serum or antibiotics) or PBS was then added to the lentiviral sediment, which was left at $2 \mathrm{hrs}$ at room temperature. Thereafter, for $30 \mathrm{mins}$ at room temperature, the packaged lentiviruses (Rlv-Sox2) were placed into 1.5-mL Eppendorf tubes (according to the dosage required for each transfection) and preserved at $-80^{\circ} \mathrm{C}$.

\section{Recombinant plasmid transfection and screening}

SGC7901-Oct4 cells in the logarithmic growth phase with a good growth state were selected for trypsin digestion and resuspension. The cells were inoculated onto a six-well plate at a density of $2 \times 10^{5} /$ well. When the cells spread to $70-80 \%$ of the well, the medium was replaced with serumfree medium. Next, the packaged lentivirus rLV-Sox2 (based on pLVX-Neo-Sox2-IRES-tdTomato) was added, with a multiplicity of infection (MOI) of 10 . The cells were incubated for $2 \mathrm{hrs}$, and the medium was then replaced with complete medium. When the cells began adhering to the wall, they were added to complete medium containing 1,000 $\mu \mathrm{g} / \mathrm{mL}$ G418 (geneticin, for the selection of stably transfected cells) and cultured for 2 weeks. DNA was extracted for PCR identification until we obtained the genome for SGC7901-Oct4-Sox2.

\section{Groups}

There were three groups: the SGC7901-ZPP (negative control group), SGC7901 group (blank control group), and SGC7901-Oct4-Sox2 group (experimental group).

\section{Semiquantitative RT-PCR}

DNA was extracted using a mass plasmid extraction kit (Qiagen, Shanghai, China). The concentration and purity were then calculated according to the OD260/OD280 ratio, and the DNA was then preserved in $20^{\circ} \mathrm{C}, \mathrm{RT}-\mathrm{PCR}$ was then conducted, using a FastQuant RT Kit (TIANGEN BIOTECH) according to the manufacturer's instructions. At the end of the reaction, PCR products were placed at $4^{\circ}$ C. The PCR products were identified by $3 \%$ agarose gel electrophoresis, and gel imager was then used to observe and record the results. The extended segment length was 954 bp.

\section{Extraction of total RNA and RT-PCR}

RNA was extracted and reverse transcribed using a TRIzol total RNA extraction kit and PrimeScript RT Enzyme Mix I (x200), respectively, according to each set of manufacturer's instructions. Regarding the Oct4 primers, the upstream sequence was 5'-GTGGAGGAAGCT GACAACAATGAAA-3' and the downstream sequence was 5'- GACCGAGGAGTACAGTGCAGTGAAG-3'. For glyceraldehyde 3-phosphate dehydrogenase (GAPDH), the product size was about $226 \mathrm{bp}$, and the upstream primer sequence was 5'-GAAGGTGAAGGTCGGAGTC-3' and the downstream sequence was 5'-GAAGATGGT GATGGGATTTTTTTC-3'. After RT-PCR, $5 \mu \mathrm{L}$ reaction product was taken and used to perform $2 \%$ agarose gel electrophoresis, and the GEL imaging analysis system (GEL DOCXR type) was used to observe and record the results.

\section{Western blotting}

Cell proteins were extracted using RIPA lysis buffer. Western blotting was performed using the standard procedure. The primary antibodies used for the analysis were anti-OCT4, anti-SOX2, anti-CD44, anti-E-cadherin, and anti- $\beta$-actin antibodies. Goat anti-mouse/rabbit double antibodies were used as secondary antibodies. The enhanced chemiluminescence (ECL) method was used for coloration, radiography, and observation. 


\section{MTS assay to assess proliferation ability}

For the MTS (3-(4,5-dimethylthiazol-2-yl)-5-(3-carboxymethoxyphenyl)-2-(4-sulfophenyl)-2H-tetrazolium) assay, a single cell suspension was formulated using complete medium without penicillin (10\% FBS+90\% RPMI 1640). The suspension was inoculated into a 96-well plate (200 $\mu \mathrm{L} /$ well), with five wells in each group. After culture for 1 , 2 , and 3 days in complete medium, $20 \mu \mathrm{L}$ MTS solution was added to each well and left for $4 \mathrm{hrs}$. OD at $490 \mathrm{~nm}$ was selected to assess the absorbance of each well using an enzyme-linked immunometric meter, with the SGC7901 group (blank control group) set to zero.

\section{MTS test to assess the drug inhibition rate}

Cells in the logarithmic growth stage $\left(5 \times 10^{4} / \mathrm{mL}\right)$ were inoculated onto a 96-well plate, and $200 \mu \mathrm{L}$ oxaliplatin (L-OHP; $0.1,0.2,0.4,0.8,1.6,3.2$, or $6.4 \mu \mathrm{g} / \mathrm{mL}$ ) or fluorouracil $(5-\mathrm{FU} ; 1,2,4,8,16,32$, or $6.4 \mu \mathrm{g} / \mathrm{mL})$ diluted with culture medium was added (three wells for each concentration). The control group was adding cell suspension only. When the time point was reached, $20 \mu \mathrm{L}$ MTS was added into each well to culture at $37^{\circ} \mathrm{C}$ for 2.5 hrs. OD $490 \mathrm{~nm}$ was assessed using an enzyme-linked immune detector to calculate the cell inhibition rate (cell inhibition rate $\left.(\%)=1-\mathrm{OD}_{\text {experimental }} / \mathrm{OD}_{\text {control }} \times 100 \%\right)$.

\section{Scratch-wound migration assay}

Cells were plated on a six-well plate $\left(5 \times 10^{5}\right.$ cells $\left./ \mathrm{mL}\right)$. After the cells spread over the plate, a pipette was used to draw a horizontal line at the back of the six-well plate, then the plate was washed with PBS and placed in an incubator containing serum-free RPMI 1640 medium for $24 \mathrm{hrs}$. An optical microscope was used to observe migration at 0 and $24 \mathrm{hrs}$, and the results were photographed. ImageJ software was used to measure the width of the scratch area at 0 and $24 \mathrm{hrs}$. The speed of cell migration (representing migration ability) was quantitatively compared between groups by calculating the difference in the distance between the two edges of the scratch between 0 and $24 \mathrm{hrs}$.

\section{Transwell assay to detect invasiveness}

First, $100 \mu \mathrm{L}$ serum-free culture medium was added to the upper transwell chamber, while $600 \mu \mathrm{L}$ culture medium containing 20\% FBS was added to the lower transwell chamber. Next, $200 \mu \mathrm{L}$ SGC7901-ZPP, SGC7901, and SGC7901-Oct4-Sox 2 suspension $\left(2 \times 10^{5} / \mathrm{mL}\right)$ was added to the upper chamber, respectively. After 20-24 hrs of regular culture, the cells were fixed, stained, dried, and counted.

\section{Transwell assay to assess migration}

The cells were starved for 12-24 hrs. Culture medium containing $600 \mu \mathrm{L} 20 \%$ serum concentration was then added into every well of a 24 -well plate. Next, $200 \mu \mathrm{L}$ cell solution $\left(2 \times 10^{5} / \mathrm{mL}\right)$ was added into the transwell chamber, and the chamber was placed into the transwell well. After culturing in an incubator, we calculated the number of cells that penetrated the membrane at different time points, wiped off the cells in the inner chamber using a cotton swab, fixed the migrated cells using methanol, stained the cells using crystal violet, and observed the semipermeable membrane using a microscope.

\section{Spherical clone formation assay}

First, $1 \times 10^{3}$ SGC7901, SGC7901-ZPP, and SGC7901-Sox 2-Oct4 were incubated in ultra-low attachment six-well plates and cultured in serum-free medium consisting of DMEM/F12 (1:1), B27 (2\%), EGF (20 ng/mL), and bFGF $\left(20 \mathrm{ng} / \mathrm{mL}\right.$ ) at $37^{\circ} \mathrm{C}$ in a humidified atmosphere of $5 \%$ $\mathrm{CO}_{2}$. The formation of spherical clones was monitored every day.

\section{Tumor formation experiment in nude mice}

First, $21 \mathrm{NOD} / \mathrm{SCID}$ mice were randomly divided into three groups, with seven per group. Next, $0.1 \mathrm{~mL} 1 \times 10^{7} /$ $\mathrm{mL}$ cell suspension of SGC7901, SGC7901-ZPP, and SGC7901-Sox2-Oct4 was injected into the back of each nude mouse. During the first 4 weeks, tumors were observed, measured, and recorded every day. At the end of fourth week, each mouse was euthanized (by cervical dislocation), and the tumor was removed for weighing.

\section{Statistical analysis}

Statistical analyses were performed using SPSS 16.0 for Windows (SPSS 16, Chicago, IL, USA). Continuous data were expressed as median and IQR or mean and SD. $P<0.05$ was considered statistically significant.

\section{Results}

\section{Construction and identification of pLVX-Neo-Sox2-IRES-tdTomato}

The target gene Sox 2 was amplified using PCR, and EcoRI and NotI enzymes were used to introduce the Sox2 gene into the lentiviral overexpression plasmid, pLVX-Neo-IRES-tdTomato, to obtain pLVX-Neo-Sox2- 
IRES-tdTomato. This plasmid was then transformed into E. coli JM109 cells for amplification. The plasmids were then extracted, and using the EcoRI and NotI enzymes, we obtained a 954 pb band (representing the correct recombinant clone). The recombinant clone plasmids were then validated by sequencing. The plasmids were packaged into lentiviruses (rLV-Sox2). As shown in Figure 1, the selected clones were the correct recombinant clone plasmids.

\section{Lentiviral packaging and titer}

The pLVX-Neo-Sox2-IRES-tdTomato vector containing the target gene, Sox2, was introduced into $293 \mathrm{~T}$ cells to get lentiviruses (rLV-Sox2), which produced a high
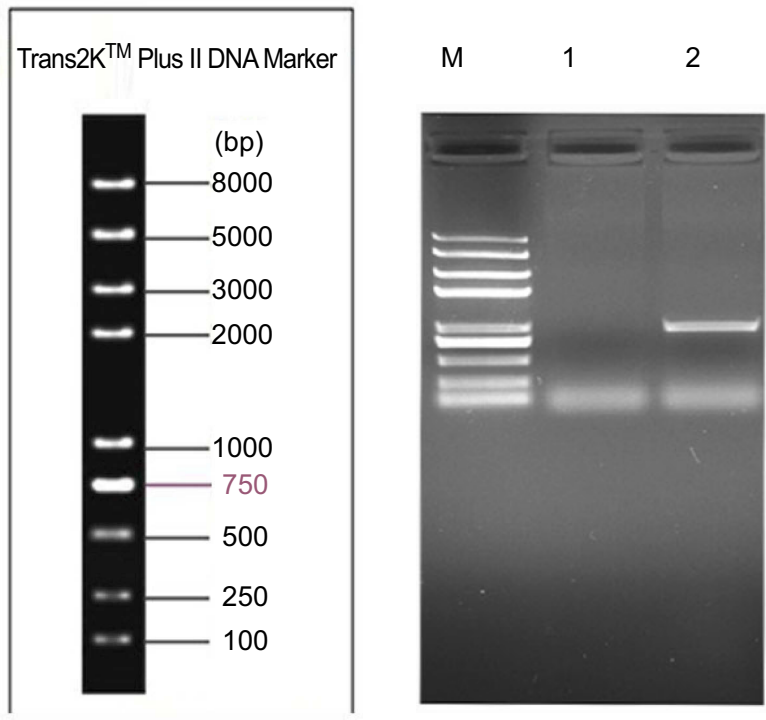

Figure I Identification result of plasmid enzyme digesting the pLVX-Neo-hSox2-IREStdTomato.Lane M: Trans2K plus marker; Lanel,2: Identification result of EcoRI+Notl double enzyme digesting the pLVX-Neo-hSox2-IRES-tdTomato.

Abbreviations: pLVX, lentiviral vector; Neo, neomycin; hSox2, sex determining region Y-box 2; IRES, internal ribosome entry site. lentivirus titer. After $24 \mathrm{hrs,} 293 \mathrm{~T}$ cells emitting red fluorescence were observed under a fluorescence microscope. As shown in Figure 2, at low magnification (100x), more than $50 \%$ of the 293T cells emitted red fluorescence, and the cells had good morphology and growth. As shown in Figure 3, 48 hrs after medium change, the rate of red fluorescence increased compared with the previous rate, and the cells had good morphology and growth. The titer of the lentivirus rLV-Sox2 was $2.0 \times 10^{7} \mathrm{TU} / \mathrm{mL}$.

\section{Transfection of SGC790I-Oct4 cells with a lentiviral vector to construct the stably transfected cell line SGC790I-Oct4-Sox2}

1. SGC7901-Oct4 was transfected with the lentivirus rLV-Sox 2 for $48 \mathrm{hrs,} \mathrm{and} \mathrm{then} \mathrm{SGC7901-}$ Oct4-Sox2 was screened for (using G418). After $48 \mathrm{hrs}$, the cells emitting red fluorescence were observed using a fluorescence microscope. As shown in Figure 4, the red fluorescence and white light images were compared, and more than $50 \%$ of the cells were emitting red fluorescence. As shown in Figure 5, 6 hrs after SGC7901-Oct4-Sox2 was screened for (using G418), the red fluorescence and white light images were compared, and over $70 \%$ of the cells were successfully stably transfected. As shown in Figure 6, before the SGC7901-Oct4Sox 2 cells were frozen, the red fluorescence and white light images were compared, and the cells had good morphology and growth.

2. PCR identification of the genome of the SGC7901Oct4-Sox2 cells.

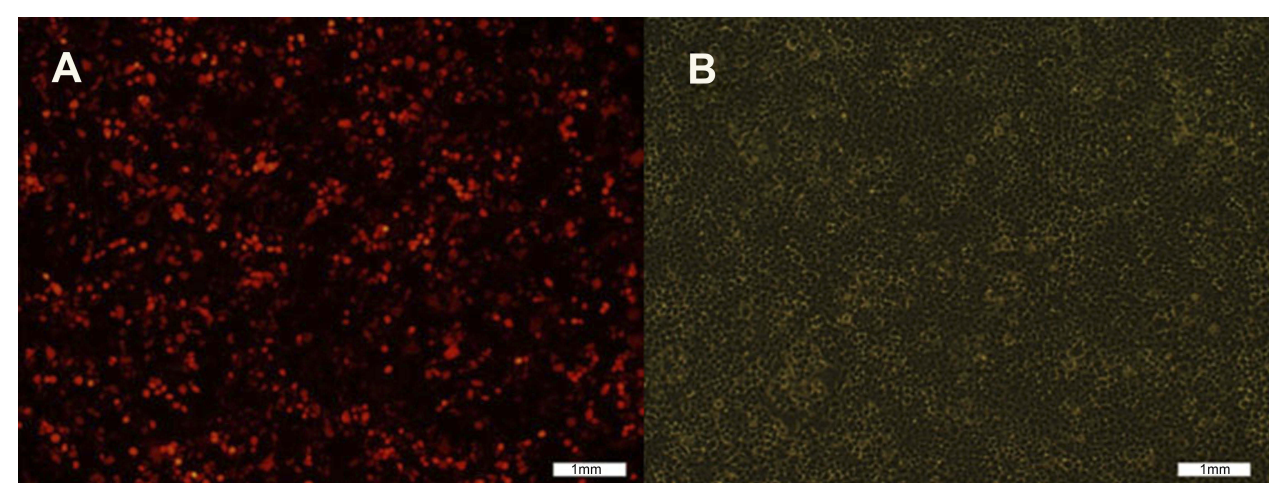

Figure 2 Cell transfection image: pLVX-Neo-hSox2- IRES-tdTomato was transfected into 293T cells before medium change. (A) Red fluorescence image; (B) White fluorescence image. 


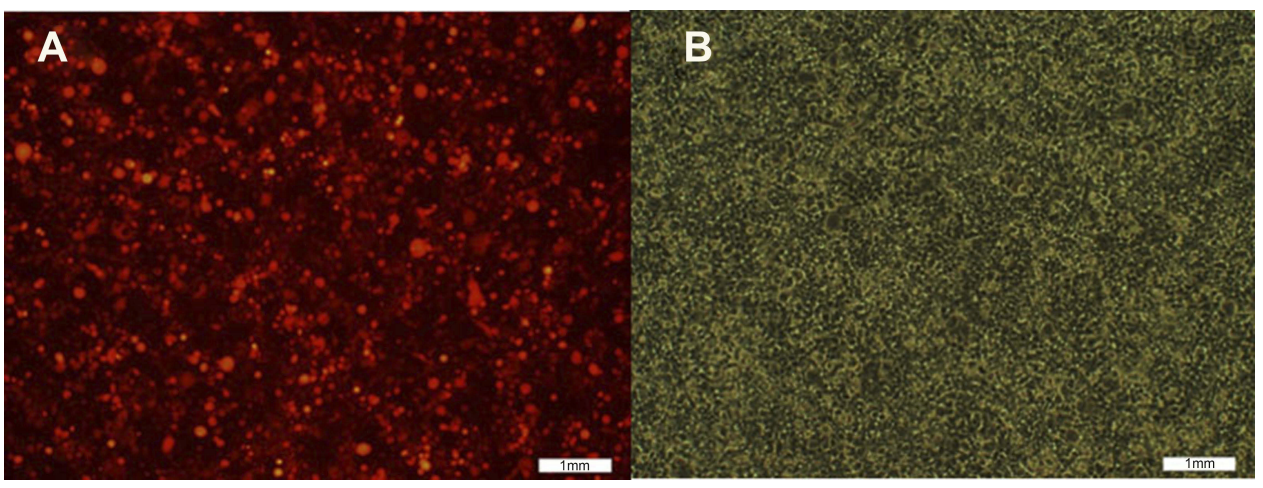

Figure 3 Cell transfection image: pLVX-Neo-hSox2- IRES-tdTomato at the 48th hour after medium change. (A) Red fluorescence image; (B) white fluorescence image.

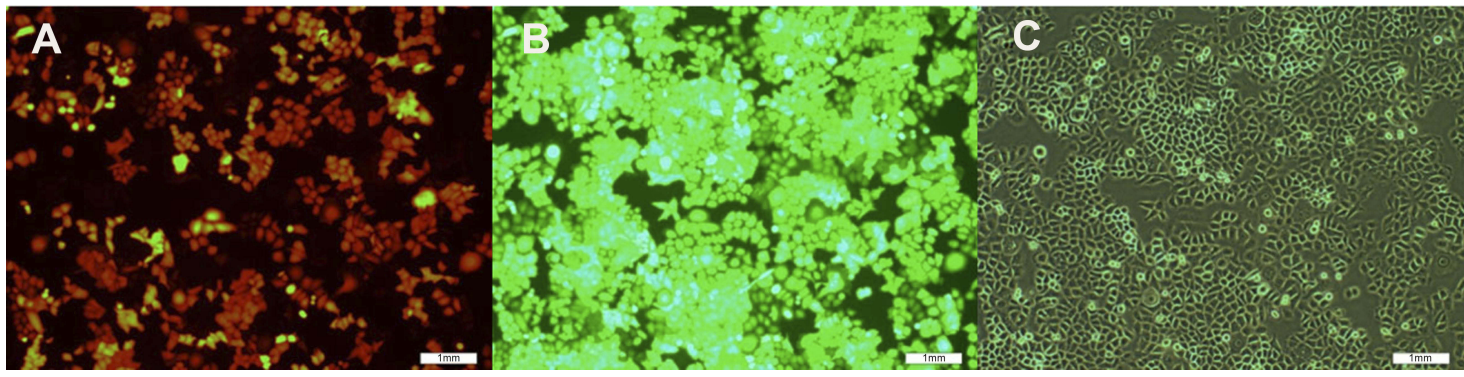

Figure 4 Image of SGC790I-0CT4 cell was infected via lentiviral rLV-Sox2 at the 48th hour. (A) Red fluorescence image; (B) green fluorescence image; (C) white fluorescence image.

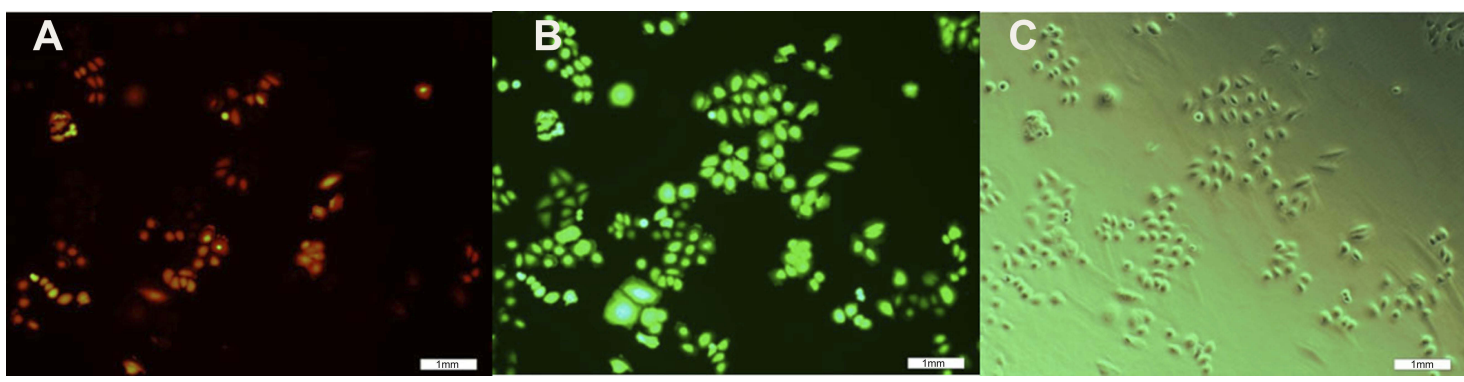

Figure 5 Image of SGC790I-0ct4-Sox2 cell line was screened using G4I8 for 6 hrs. (A) Red fluorescence image; (B) green fluorescence image; (C) white fluorescence image.

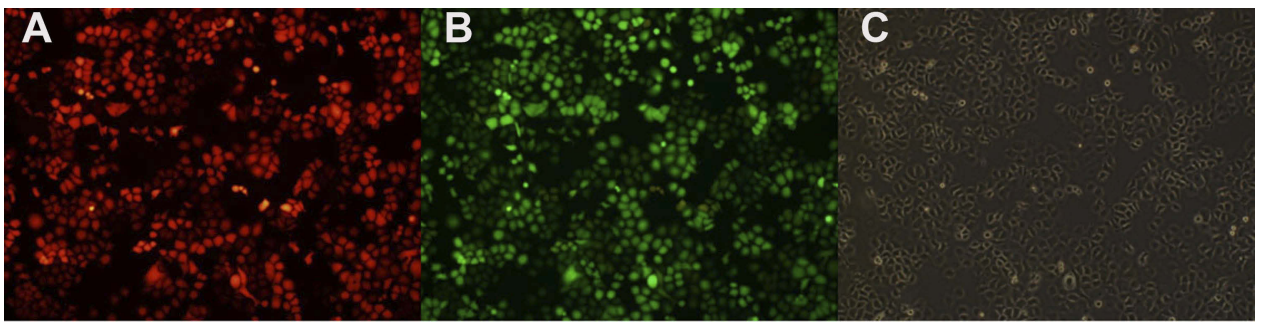

Figure 6 image of SGC790I-0ct4 Sox2 cells before freezing. (A) Red fluorescence image; (B) green fluorescence image; (C) white fluorescence image.

As shown in Figure 1, the genome of the SGC7901Oct4-Sox2 cells was amplified and the target Sox2 gene (954 bp) was obtained, indicating that a stably transfected cell line was successfully constructed (Table 1).

\section{Fluorescence quantitative PCR}

As shown in Figure 7, the mRNA expression levels of Sox2, Oct4, Klf4, c-Myc, CD44, and E-cadherin between SGC7901 and SGC7901-ZPP were not significantly different $(P>0.05)$. Compared with SGC7901 and SGC7901-ZPP, the mRNA 
Table I The result and analysis of PCR

\begin{tabular}{|l|l|l|l|}
\hline Number & Name & Length & $\begin{array}{l}\text { Right or } \\
\text { wrong }\end{array}$ \\
\hline M & Marker & - & - \\
\hline & Blank control (SGC790I) & - & Right \\
& $\begin{array}{l}\text { Genome (SGC790I-OCT } \\
\text { 4-SOX2) }\end{array}$ & $954 \mathrm{bp}$ & Right \\
\hline
\end{tabular}

expression levels of Sox2, Oct4, CD44, and E-cadherin in SGC7901-Oct4-Sox2 were significantly higher $(P<0.05)$. However, no significant differences were found in the mRNA expression levels of Klf4 and c-Myc among SGC7901, SGC7901-ZPP, and SGC7901-Oct4-Sox2 $(P>0.05)$ (Table 2). The results indicated that overexpression of Oct 4 and Sox 2 increased the expression of stem cell markers (CD44 and E-Cadherin) in SGC7901.

\section{Western blotting}

As shown in Figure 8 and Table 3, compared with SGC7901 and SGC7901-ZPP, the expression of the
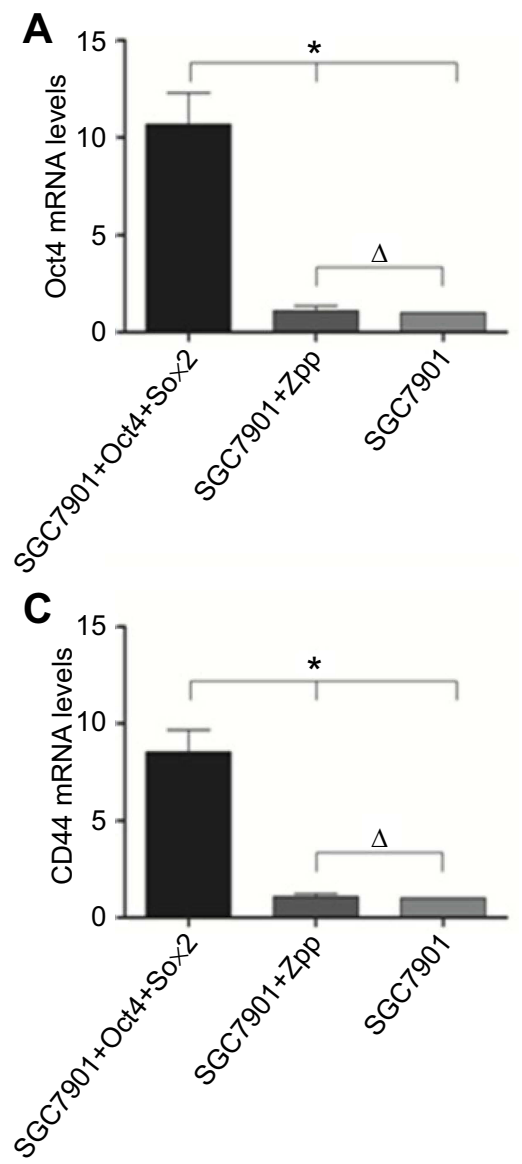

Table 2 The miRNA expression level of gastric cancer stem cell marker gene c-Myc, KIf4 among SGC790I, SGC790I-ZPP, and SGC790I-Oct4-Sox2

\begin{tabular}{|l|l|l|l|}
\hline Group & SGC790I & $\begin{array}{l}\text { SGC790I- } \\
\text { ZPP }\end{array}$ & $\begin{array}{l}\text { SGC790I-OCT4- } \\
\text { SOX2 }\end{array}$ \\
\hline c-Myc & $1.00 \pm 0.00$ & $1.17 \pm 0.16$ & $1.09 \pm 0.19$ \\
Klf4 & $1.00 \pm 0.00$ & $1.30 \pm 0.11$ & $1.01 \pm 0.21$ \\
\hline
\end{tabular}

Sox2, Oct4, CD44, and E-cadherin proteins in SGC7901Oct4-Sox2 was significantly higher $(P<0.05)$, which was consistent with the fluorescence quantitative PCR results.

\section{MTS assay to assess cell proliferation ability}

As shown in Table 4 and Figure 9, on the first day, there were no significant differences in the relative absorbance among SGC7901, SGC7901-ZPP, and SGC7901-Oct4-Sox2 $(P>0.05)$. On the second and third day, SGC7901-ZPP and SGC7901 showed no significant difference in relative absorbance $(P>0.05)$, compared with SGC7901-ZPP and
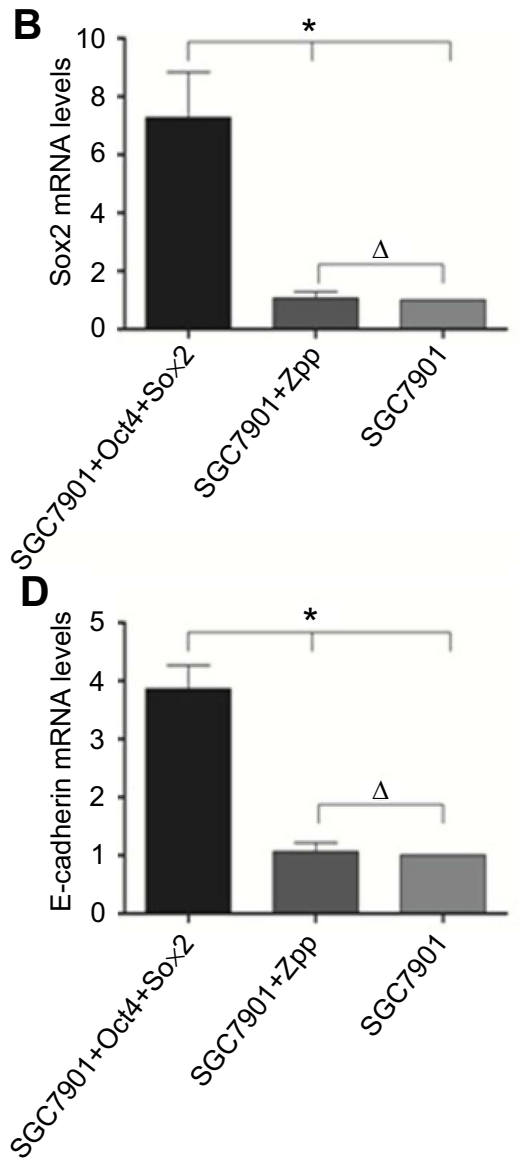

Figure 7 Compared the miRNA expression level of gastric cancer stem cell marker gene Sox2, Oct4, CD44, E-cadherin among SGC790I, SGC790I -ZPP and SGC790I - Oct4 Sox2. $(* \mathrm{P}<0.05, \Delta \mathrm{P}>0.05)$.

Abbreviations: Sox2, sex determining region Y-box 2; Oct4, octamer-binding protein 4; CD44,clusterofee 


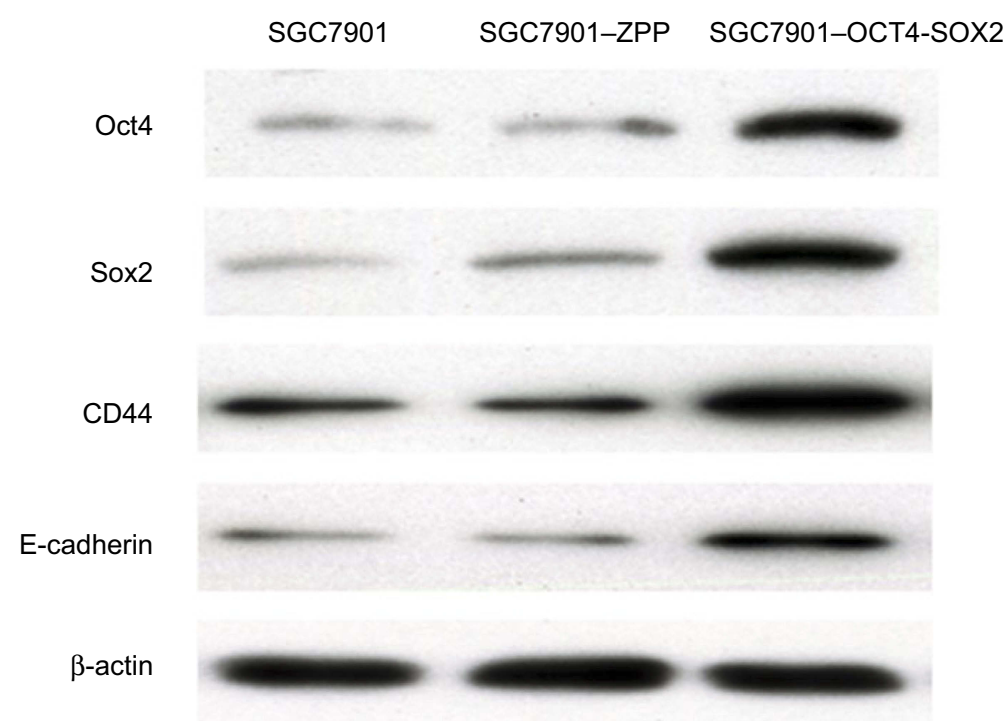

Figure 8 The expression of Sox 2 protein, Oct4 protein, CD44 protein, and E-cadherin.

Table 3 Western blot to detect and compare the expression of Sox2 protein, Oct4 protein, CD44 protein, and E-cadherin among SGC790I, SGC790I-ZPP, and SGC790I-Oct4-Sox2 based on the expression of $\boldsymbol{\beta}$-actin

\begin{tabular}{|l|l|l|l|}
\hline Group & SGC790I & $\begin{array}{l}\text { SGC790I- } \\
\text { ZPP }\end{array}$ & $\begin{array}{l}\text { SGC790I-OCT4- } \\
\text { SOX2 }\end{array}$ \\
\hline Oct4 & $0.26 \pm 0.03$ & $0.28 \pm 0.03$ & $0.74 \pm 0.12$ \\
Sox2 & $0.29 \pm 0.05$ & $0.31 \pm 0.06$ & $0.86 \pm 0.21$ \\
CD44 & $0.44 \pm 0.03$ & $0.41 \pm 0.06$ & $0.91 \pm 0.16$ \\
E-cadherin & $0.24 \pm 0.02$ & $0.25 \pm 0.05$ & $0.71 \pm 0.11$ \\
\hline
\end{tabular}

Table 4 After culturing for 4 days, the relative absorbance value (OD value) was measured daily among the SGC790I,SGC790IZPP and SGC790I-Oct4-Sox2

\begin{tabular}{|l|l|l|l|l|}
\hline Group & I day & 2 days & 3 days & 4 days \\
\hline SGC790I & $0.88 \pm 0.03$ & $1.13 \pm 0.06$ & $1.49 \pm 0.07$ & $1.69 \pm 0.06$ \\
SGC790I-ZPP & $0.90 \pm 0.27$ & $1.09 \pm 0.10$ & $1.56 \pm 0.15$ & $1.74 \pm 0.08$ \\
SGC790I-OCT & $1.02 \pm 0.14$ & $1.41 \pm 0.08$ & $1.91 \pm 0.21$ & $1.77 \pm 0.16$ \\
4-SOX2 & & & & \\
\hline
\end{tabular}

SGC7901, and the relative absorbance of SGC7901-Oct4Sox 2 was significantly higher $(P<0.05)$. On the fourth day, there were no significant differences in relative absorbance among the three groups $(P>0.05)$. The probable reason for this result on the fourth day is that the cells proliferated and spread over the wells of the 96-well plate, which led to a lack of space to proliferate further. The MTS assay indicated that overexpression of Oct 4 and Sox 2 improved the proliferation ability of the gastric cancer SGC7901 cells.

\section{MTS assay to detect drug resistance}

As shown in Figure 10, after L-OHP was administered to the three groups, the half maximal inhibitory concentration (IC50) of SGC7901, SGC7901-ZPP, and SGC7901-Oct4Sox2 was $0.73 \pm 0.12,0.76 \pm 0.09$, and $2.54 \pm 0.14 \mu \mathrm{g} / \mathrm{mL}$, respectively. After 5-FU was administered to the three groups, the IC50 of SGC7901, SGC7901-ZPP, and SGC7901-Oct4-Sox2 was $2.27 \pm 0.3,2.34 \pm 0.11$, and 10.57 $\pm 2.0 \mu \mathrm{g} / \mathrm{mL}$, respectively. There were no significant differences in drug resistance between SGC7901 and SGC7901ZPP ( $P>0.05)$. Compared with SGC7901-ZPP and SGC7901, SGC7901-Oct4-Sox2 had significantly higher L-OHP and 5 -FU resistance $(P<0.05)$. This indicated that overexpression of Oct4 and Sox 2 led to stronger drug resistance.

\section{Scratch-wound migration assay}

As shown in Figure 11, the migration distance of SGC7901, SGC-7901-ZPP, and SGC-7901-Oct4-Sox2 was 0.211 $\pm 0.014,0.208 \pm 0.020$, and $0.854 \pm 0.090 \mathrm{~mm}$, respectively. There was no significant difference between SGC7901 and SGC7901-ZPP ( $P>0.05)$. Compared with SGC7901 and SGC7901-ZPP, the migration ability of SGC7901-Oct4-Sox 2 was significantly higher $(P<0.05)$. This indicated that overexpression of Oct 4 and Sox 2 led to a greater migration ability.

\section{Transwell invasion assay}

As shown in Figure 12, the mean number of SGC7901, SGC7901-ZPP, and SGC-7901-Oct4-Sox2 cells invading and passing through the basement membrane was $76.67 \pm 2.26,76.00$ 


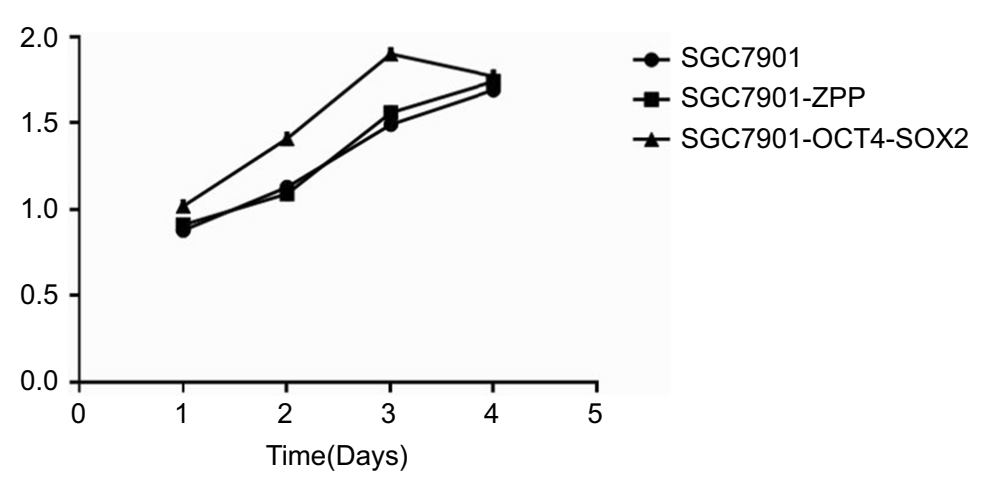

Figure 9 The growth curve of SGC790I, SGC790I -ZPP, and SGC790I -Oct4 -Sox2.

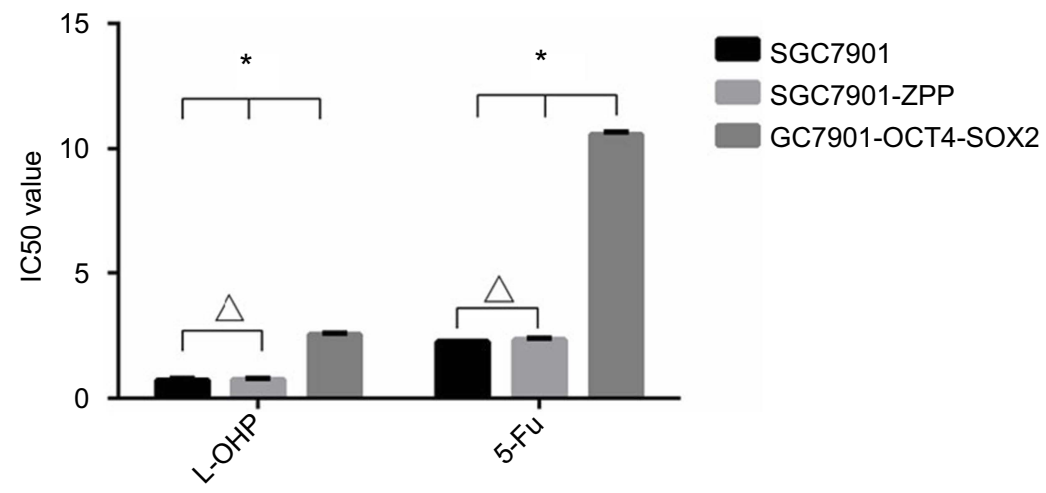

Figure 10 The effect of L-OHP and 5-FU on the activity of SCC790I, SGC790I-ZPP and SGC790I-Oct4-Sox2. $(* P<0.05, \Delta P>0.05)$. Abbreviations: L-OHP,oxaliplatin; 5-FU,5-fluorouracil.

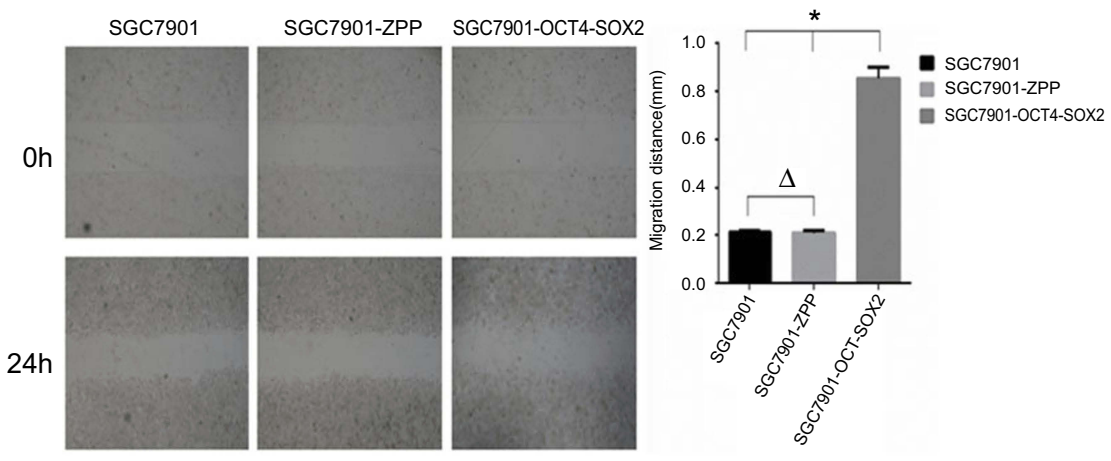

Figure II (A) The cell migration image of the 0th and the 24th (B) Comparison of the migration distance among SGC790I. SGC-790I-ZPP and SGC790I-Oct4-Sox2. Notes: $* P<0.05, \Delta P>0.05$.

\pm 3.39 , and $146.67 \pm 7.42$, respectively. There were no significant differences between SGC7901 and SGC7901-ZPP $(P>0.05)$. Compared with SGC7901-ZPP and SGC7901, the invasion ability of SGC7901-Oct4-Sox2 was significantly increased $(P<0.05)$. This indicated that overexpression of Oct4 and Sox2 led to greater invasion ability.

\section{Transwell migration assay}

As shown in Figure 13, the mean number of SGC7901, SGC-7901-ZPP, and SGC-7901-Oct4-Sox2 cells passing through the basement membrane was $35.33 \pm 2.99,36.00$ \pm 3.39 , and $86.50 \pm 3.39$, respectively. Compared with SGC7901 and SGC7901-ZPP, the migration ability of SGC7901-Oct4-Sox2 was significantly increased $(P<0.05)$. This showed that overexpression of Oct4 and Sox2 led to a greater migration ability.

\section{Spherical clone formation assay}

As shown in Figure 14, the number of SGC7901, SGC7901-ZPP, and SGC-7901-Oct4-Sox2 cells exhibiting 

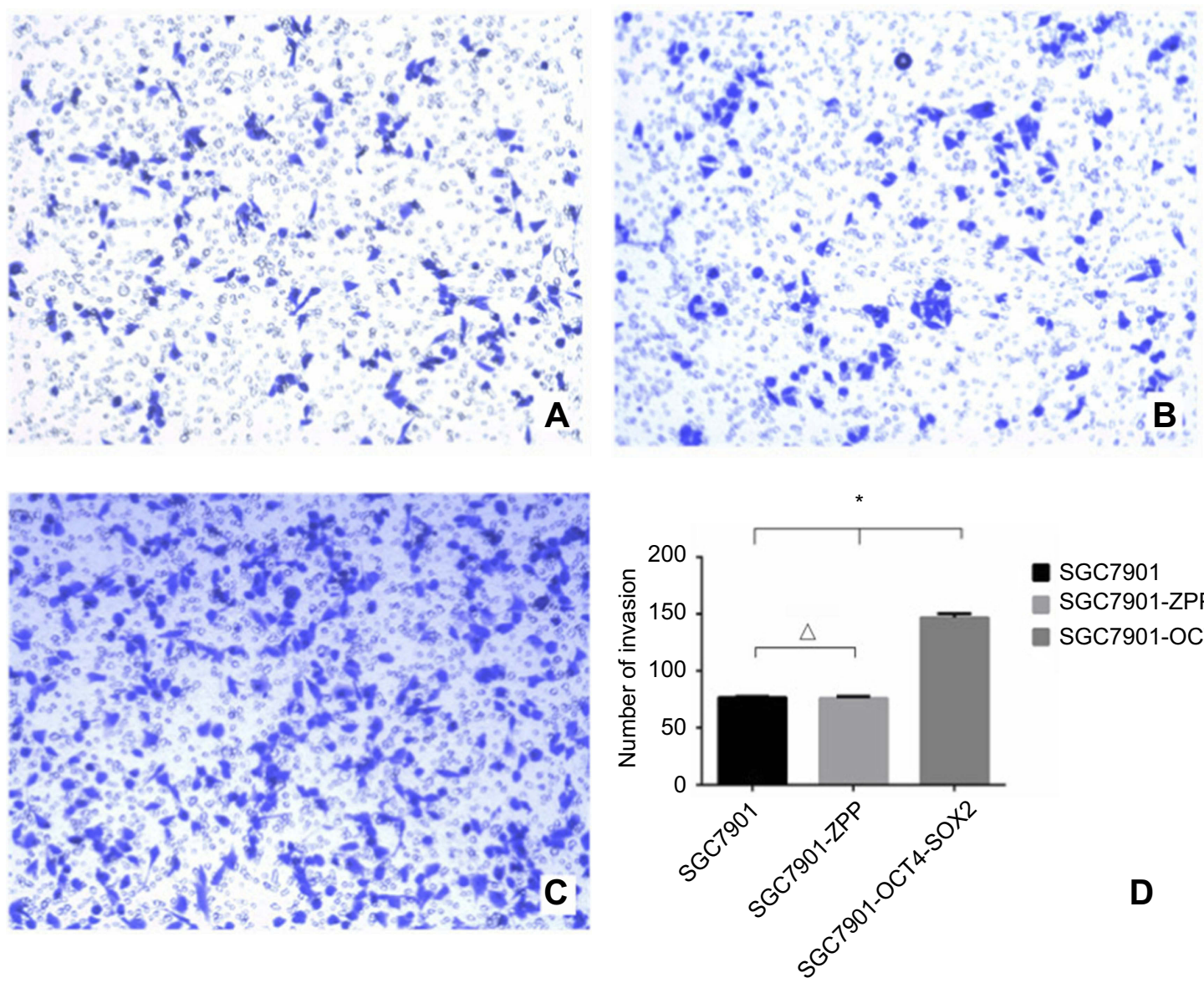

SGC7901

SGC7901-ZPP

SGC7901-OCT4-SOX2

Figure 12 (A) $0.1 \%$ crystal violet staining image that SGC790I invaded and passed through the basement membrane; (B) $0.1 \%$ crystal violet staining image that SGC790IZPP cells invaded and passed through the basement membrane; (C) $0.1 \%$ crystal violet staining image that SGC790I-0CT4-SOX2 cells invaded and passed through the basement membrane; (D) cell counting bar graph that cells invaded and passed through the basement membrane among the three groups.

spherical formation was $5.67 \pm 1.13,4.67 \pm 1.13$, and 63.05 \pm 6.30 , respectively. Compared with SGC7901 and SGC7901-ZPP, the tumorigenic ability of SGC7901-Oct4Sox 2 was significantly stronger $(P<0.05)$. This indicated that overexpression of Oct4 and Sox2 led to greatly enhanced tumorigenic ability.

\section{Tumor formation experiment in nude mice}

As shown in Figure 15, compared with SGC7901-ZPP and SGC7901 (Figure 15A and B), the size of the transplanted tumor for SGC7901-Oct4-Sox2 (Figure 15C) was larger, with a diameter of more than $1.0 \mathrm{~cm}$. After 4 weeks, the transplanted tumors were removed for weighing, and the weight for SGC7901, SGC7901-ZPP, and SGC7901-Oct4Sox 2 was $0.216 \pm 0.020,0.219 \pm 0.026$, and $0.791 \pm 0.044 \mathrm{~g}$, respectively (Figure 15D). There were no significant differences in the tumor weight between SGC7901-ZPP and SGC7901 $(P>0.05)$. Compared with SGC7901-ZPP and
SGC7901, the weight for SGC7901-Oct4-Sox2 was significantly heavier $(P<0.05)$. This showed that overexpression of Oct 4 and Sox 2 led to a greater tumorigenic ability.

\section{Discussion}

In China, cancer is a serious disease that damages human health, with an annual morbidity rate of 235 in 23 per 100,000 people and a mortality rate of 148 in 81 per 100,000 people. ${ }^{8}$ With continuous medical improvement, progress has been made in the field of gastric cancer. However, the research on the pathogenesis and treatment of gastric cancer is still not ideal, and the overall survival rate and mortality rate have still not been greatly improved. With the continuous exploration of stem cells, the relationship between stem cells and cancer has become more and more obvious. Many people believe that cancer is a type of stem cell-related disease, which provides a new approach for the research and treatment of gastric cancer. 

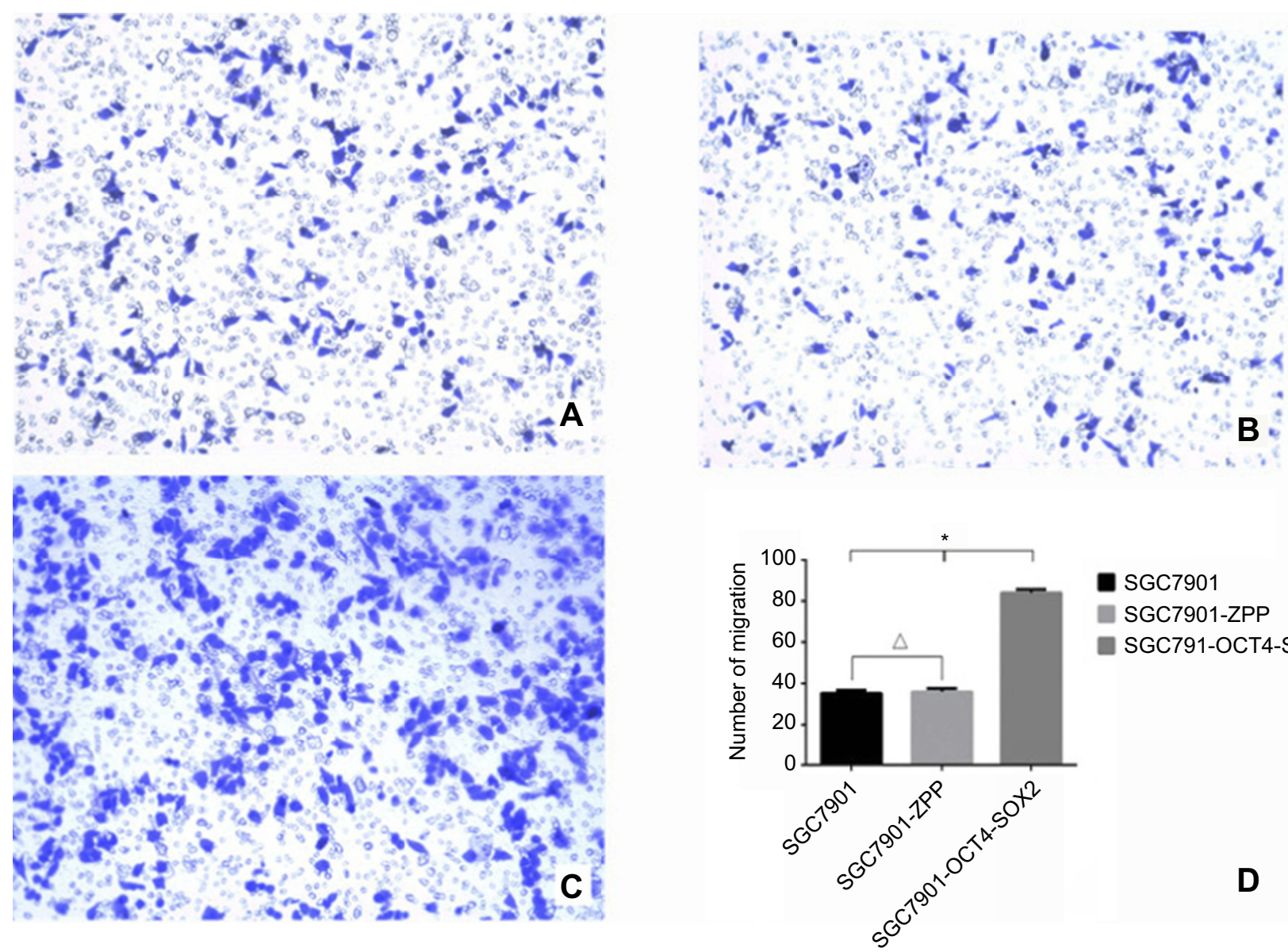

SGC7901

SGC7901-ZPP

SGC791-OCT4-SOX2

Figure I3 (A) $0.1 \%$ crystal violet staining image that SCC790I cells migrated and passed through the basement membrane; (B) $0.1 \%$ crystal violet staining cell image that SGC790IZPP cells migrated and passed through the basement membrane; (C) $0.1 \%$ crystal violet staining cell image that SGC790I-OCT4-SOX2 cells migrated and passed through the basement membrane; (D) Cell counting bar graph that cell migrated and passed through the basement membrane among three groups.

Stem cells can be divided into embryonic and adult stem cells. The concept of cancer stem cells (CSCs) was proposed in the last century. Recent studies indicate that cancer cells can be categorized into many types, ranging from malignant CSCs, which have unlimited proliferative potential (and they are thought to be the only cells with unlimited proliferation potential), to differentiated cancer cells, which have limited proliferative potential. Therefore, CSCs are considered to be responsible for cancer invasion, metastasis, and drug resistance. ${ }^{9}$ In recent years, many literature have reported the relationships between CSCs and solid tumors such as breast cancer, ${ }^{10}$ brain tumor, ${ }^{11}$ prostate cancer, ${ }^{12}$ melanoma, ${ }^{13}$ and colon cancer. ${ }^{14}$ However, there are few studies on the relationship between CSCs and gastric cancer. The cause of many types of cancer is the mutation of adult cells. However, gastrointestinal epithelial cells renew rapidly, which is hard for them to lead to long-term malignant lesions, on the contrary, the lifespan of stem cells is very long and it is easier for them to accumulate mutations. Therefore, it is widely believed that it is the mutation of adult stem cells that leads to the onset of gastric cancer. ${ }^{15}$

Sox2 is a member of the SOX family and belongs to group B, together with SOX1, SOX3, and SOX14. SOX2 is usually considered as a carcinogenic factor. It plays a regulatory role in the development of early embryos and plays key roles in maintaining progenitor cell self-renewal, ensuring stem cell versatility, and determining the fate of cells. In addition, Sox 2 is indispensable for maintaining homeostasis in the body. ${ }^{16}$ Kurda et $\mathrm{al}^{17}$ found that some embryonic stem cells specifically express SOX2-binding factor, which binds to Oct4 and thereby plays a role in transcription regulation; thus the expression of Nanog was upregulated. Sox2 also plays an important role in tumor formation 

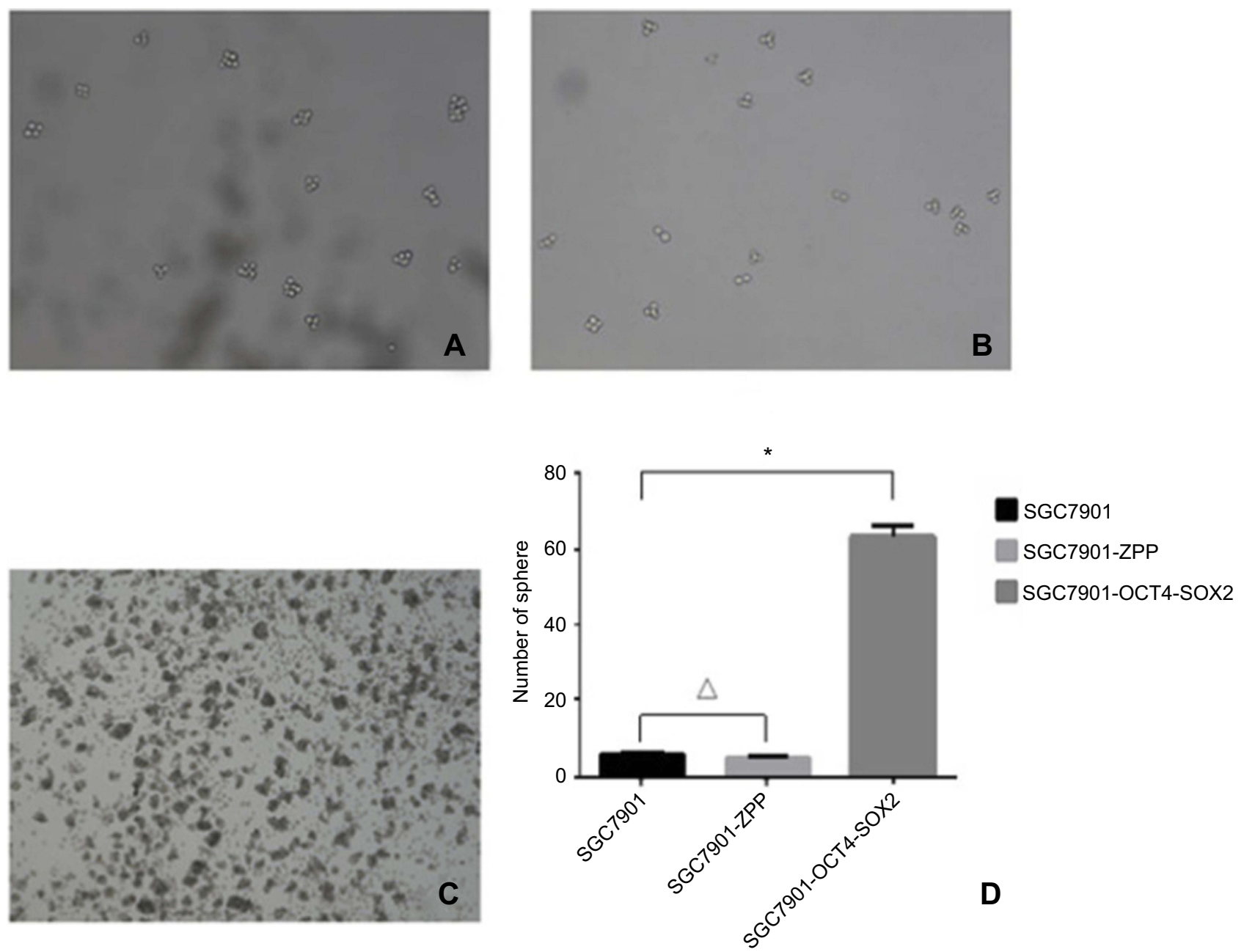

Figure 14 Tumor cell ball image that cells in each group were suspension cultured for 14 hrs. (A) SGC790I; (B) SCG790I-ZPP; (C) SCG790I-0CT4-SOX2; (D) Tumor cell ball bar graph.

and development. It was found that the expression level of Sox 2 in glioblastoma tissues was significantly higher than in normal brain tissues, and when Sox 2 was interfered with, the tumorigenic and proliferative capacity of the glioblastoma cells were reduced. ${ }^{18}$ Theresia et al ${ }^{19}$ found that Sox 2 is highly expressed in lung squamous cell carcinoma, and it causes differentiated squamous cell carcinoma to lose its ability to further differentiate. The expression level of Sox 2 is negatively correlated with the degree of lung cancer differentiation. ${ }^{20}$ Similarly, Lengerke et $\mathrm{al}^{21}$ found that the expression level of Sox 2 in breast cancer tissues was significantly higher than that in normal breast tissue, and the expression level affects the 5-year survival rate. In breastinfiltrating ductal carcinoma, the expression levels of Sox 2 and Oct 4 are significantly related, which indicates a strongly synergic relationship between them.
The gene Oct4 (also known as OTF4, Oct3, OTF3, or POUSF1) belongs to the family of POU transcription factors and is located in the human chromosome at 6p21.3. The gene contains five exons with a length of $16.40 \mathrm{kB}$, and it has five transcription start points that can be used to transcribe different mRNAs, which are translated into a variety of proteins. During embryonic development, the expression level of Oct4 affects the differentiation and dedifferentiation of embryonic stem cells, maintaining the self-renewal ability of the embryonic stem cells. ${ }^{22}$ In terms of tumors, Oct4 is usually highly expressed in germ and embryonic tumor cells, such as germ tumor cells, asexual tumor cell seminoma, and embryonal carcinoma. ${ }^{23}$ Duinsbergen et $\mathrm{al}^{24}$ found that Oct4 could be used as a specific and sensitive marker for embryonal carcinoma and germ cell tumor, and Cheng et $\mathrm{al}^{25}$ found that Oct 4 could be used to evaluate the 

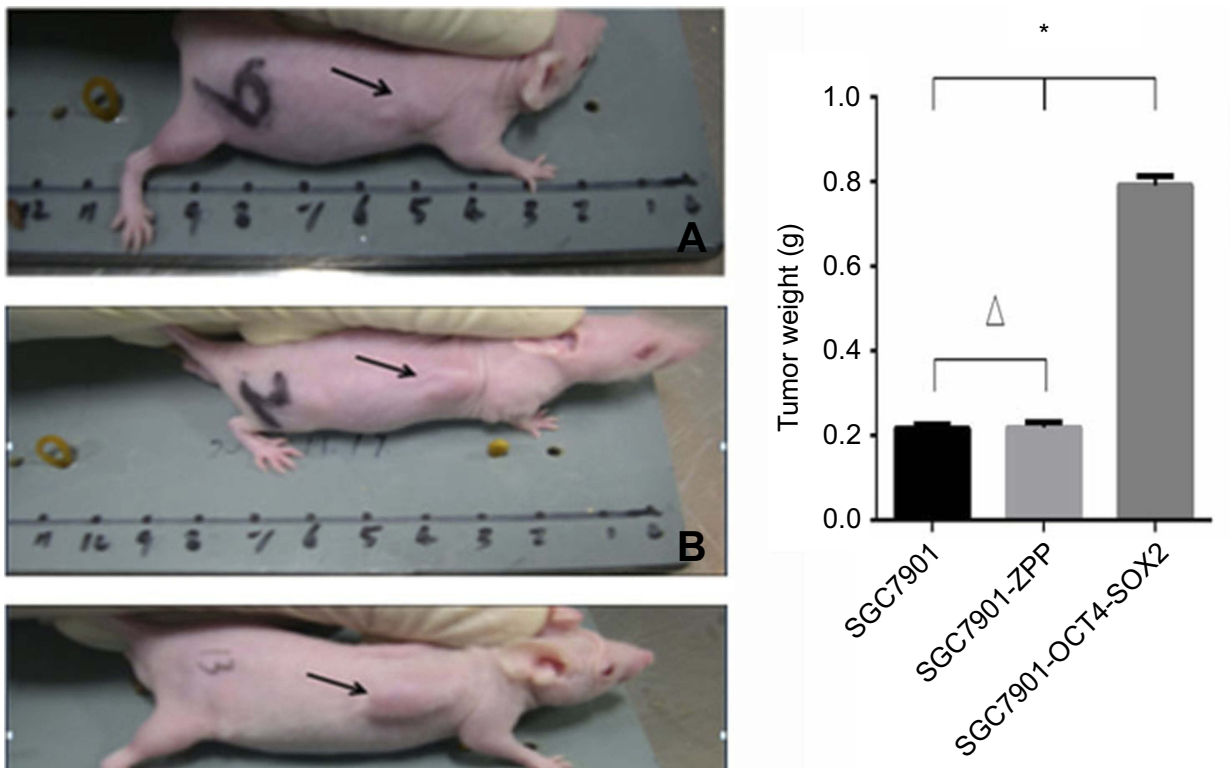

SGC7901

SGC7901-ZPP

SGC7901-OCT4-SOX2

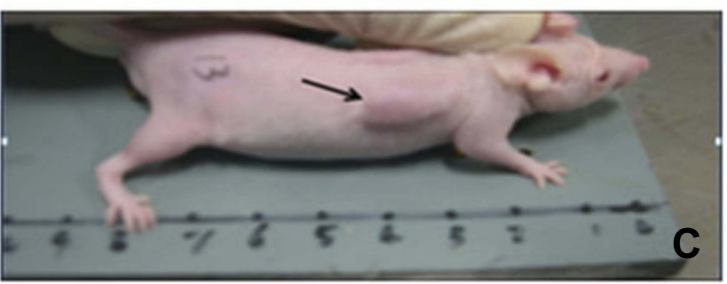

Figure 15 Tumor formation photograph that nude mice wore injected with cells after4 weeks (A) Tumor formation ofSGC790 I; (B) tumor formation ofSGC790I-ZPP; (C) tumor formation of SGC790I-OCT4-SOX2; (D) Tumor weight bar graph.

prognosis and treatment response of germ cell tumors and metastatic tumors. Additionally, it was recently found that in mouse models of breast cancer, high Oct4 expression led to increased tumorigenic ability compared to low Oct4 expression. ${ }^{26}$ Yuan et $\mathrm{al}^{27}$ found that downregulating Oct4 expression in liver cancer cells decreased their tumorigenic and invasive abilities. Karoubi et $\mathrm{al}^{28}$ found that Oct4 expression in normal lung tissues was significantly lower than that in lung adenocarcinoma and bronchial alveolar carcinoma. Saigusa et $\mathrm{al}^{29}$ found that Oct4 and Sox 2 could be used as indicators to evaluate the surgical prognosis of rectal cancer patients, with some ability to predicted recurrence and distant metastasis. Therefore, Oct4 plays an extremely important role in tumor formation and development.

In recent years, a new field has emerged, which involves induced pluripotent stem cells (iPSs) and induced pluripotent cancer cells (iPCs). In 2006, Takahashi et $\mathrm{al}^{30}$ introduced the Sox2, Oct4, c-Myc, and Klf4 genes into mice fibroblasts to reprogram them into cells labeled "iPSs", which were similar to embryonic stem cells. This discovery led to great developments in regenerative medicine, and it has provided a new approach for CSC research. With further research on iPSs, researchers gradually found that the reprogrammed cells were not necessarily limited to a specific cell type and differentiation stage, and many tissues could be reprogrammed, including somatic cells such as mouse liver cells, ${ }^{31,32}$ gastric epithelial cells, ${ }^{32,33}$ mature B lymphocytes, ${ }^{34}$ and even cancer cells. Lin et al successfully reprogrammed the human skin cancer cell lines COLO and PCS into iPCs using miRNA$302,{ }^{35}$ which were designated miRNA-induced pluripotent stem cells (mirPS cells). They are $86 \%$ similar to the human embryonic stem cell lines $\mathrm{H} 9$ and $\mathrm{H} 1$ and could be differentiated into neuronal like cells when specific factors were used during induction. Carette et $\mathrm{al}^{32}$ showed that, after introducing four genes (Sox2, Oct4, c-Myc, and Klf4), chronic myelogenous leukemia cells could also be induced into iPCs, and they could differentiate into three germ layers. Miyoshi et $\mathrm{al}^{36}$ used Sox2, Oct4, c-Myc, and Klf4 to successfully induce a pancreatic cancer cell line (MIAPaCa-2), colon cancer cell line (DLD-1, and HCT116), and liver cancer cell line (PLC) into iPCs, and they further induced iPCs in suspension into adherent cells, which were designated post-iPCs. Compared with the primary cells, the post-iPCs exhibited morphological diversity similar to mesenchymal cells, epithelial cells, and nerve cells. The proliferation and tumorigenic ability of the iPCs was decreased, and they were sensitive to differentiation induction therapy. Therefore, iPCs are of great research value in both theoretical cancer research and clinical applications. They provide a new stem cell- 
related tool to research cancer pathogenesis in order to develop new therapeutic approaches.

In the induction of iPSs and iPCs, Oct 4 and Sox 2 play very important roles. In gastric cancer, for Sox2, Tian et $\mathrm{al}^{37}$ reported that Sox 2 mRNA and protein were highly and significantly overexpressed in gastric CSCs, and knockdown of Sox2 decreased CSCs, resulting in lower tumorigenicity and decreased stem cell characteristics. This indicates that Sox 2 plays a very important role in sustaining tumorigenicity and stem cell properties. Katharina Hütz et $\mathrm{al}^{38}$ found that inhibiting SOX2 resulted in reduced cell proliferation and tumorigenicity because the cell cycle became arrested in the G2/M phase. It has also been reported that Sox 2 expression might be associated with gastric cancer invasion and the independent prognostic factors of patients with gastric cancer. ${ }^{39}$ Thus, Sox 2 plays a pivotal role in sustaining stem cell properties.

Regarding Oct4, it is overexpressed in embryonic stem cells, adult stem cells, and CSCs. ${ }^{40,41}$ Potential pluripotent stem cells could be the target cells for the initiation of CSC, and Oct4 may be associated with this process. A possible mechanism involves prevention of the downregulation of genes such as Oct4 to start this terminal differentiation process. ${ }^{42}$ Regarding gastric cancer, compared with cancer cells, OCT4 protein was overexpressed in the gastric CSC. ${ }^{43,44}$ Zhong et $\mathrm{al}^{45}$ demonstrated that overexpressing Oct4 gastric cancer cells led to selfrenewal abilities (to create new stem cells) and the maintenance of an undifferentiated status. Oct4 overexpression induces differentiated cancer cells to become undifferentiated, and then helps to maintain the cancer cells in an undifferentiated state. Tai et $\mathrm{al}^{42}$ also showed that differentiation of gastric cancer cells occurred after Oct4 was downregulated, which indicates that Oct4 could reprogram differentiated cancer cells into undifferentiated cancer cells (CSCs). Sox 2 and Oct4 are two pivotal stem cell genes. However, there are few studies showing the joint effect of Sox 2 and Oct4 on gastric CSC, so we explored the joint function of Sox 2 and Oct4 and the mechanism underlying gastric cancer.

According to previous research, Sox2, Oct4, and Nanog synergistically transcribe and encode the regulatory target genes by forming a feedforward system and cooperating with multiple signal transduction pathways. ${ }^{46}$ The binding sites of SOX2 and OCT4 are next to genes related to growth, and they may cooperate to complete the interaction of proteins via synergistic transcriptional activation of the POU structure of Oct4 with the HG structure of Sox $2{ }^{47}$ Embryonic stem cells by Wnt pathways involved in protein coding gene and TGF- $\beta$ protein are the common target genes of Oct 4 , Nanog and Sox 2 . The Wnt and TGF- $\beta$ pathways mainly maintain stem cell self-renewal and pluripotency, and the Wnt pathway participates in encoding protein and TGF- $\beta$ protein gene, which is the common target gene of Sox 2 , Oct4, and Nang. Laurie et $\mathrm{al}^{48}$ found that OCT4, SOX2, and NANOG bound together to the promoters of their own genes and formed interconnected autoregulatory loops. Therefore, we hypothesize that Oct4 and Sox2 have a synergistic effect on promoting oncological, biological, and stem cell characteristics in gastric cancer.

In this study, we overexpreessed Oct4 and Sox 2 (using a lentiviral vector) in gastric cancer cells. Using the scratch-wound migration assay and transwell migration and invasion assays, it was found that the invasion ability of gastric cancer cells overexpressing Oct 4 and Sox 2 was increased. Using an MTS assay, it was found that the proliferation ability of the cells was also significantly increased. In the tumor formation experiment in nude mice, the tumor formation of gastric cancer cells overexpressing Oct4 and Sox2 was significantly faster and the tumors were consequently larger and heavier. The results strongly show that Sox 2 and Oct 4 play important roles in the proliferation, invasion, and metastasis of gastric cancer cells. In addition, fluorescence quantitative PCR and Western blotting showed that the cytokine levels of gastric cancer cells overexpressing Oct4 and Sox2 were significantly increased. These results suggest that Sox 2 and Oct4 increase stem cell characteristics and promote the regeneration and differentiation of tissue cells. It is speculated that Sox 2 and Oct4 have a synergistic effect regarding promoting the biological, oncological, and stem cell characteristics of gastric cancer.

However, this study is not without limitations. Some clinicopathological data associated with gastric cancer, such as disease-free survival, were not included. Additionally, the detailed underlying molecular mechanisms were not determined. These limitations should be addressed in future studies.

In conclusion, Sox 2 and Oct 4 overexpression changes the biological and oncological characteristics of gastric cancer cells, enhancing the cell proliferation, migration, and invasion abilities and the stem cell characteristics. This evidence concerning Sox 2 and Oct4 may lead to new approaches for treating gastric cancer, with Sox2 and Oct4 becoming the targets for gastric cancer treatment. 


\section{Statement of Ethics}

This study and all experimental protocols were approved by the Animal Care and Use Committee of Xiamen University and carried out in accordance with the guidelines of the Animal Care and Use Committee of Xiamen University.

\section{Acknowledgments}

We would like to thank everyone who helped with this study. This study was supported by the Medical Innovations Topic in Fujian Province (no. 2016-CXB-8, and 2012-CXB-29), the Science and Technology Project of the Natural Science Foundation of Fujian Province (no. 2016J01639), and the Youth Research Development Fund Project of The First Affiliated Hospital of Xiamen University (no.XYY2017010).

\section{Author contributions}

All authors contributed to data analysis, drafting or revising the article, gave final approval of the version to be published, and agree to be accountable for all aspects of the work.

\section{Disclosure}

The authors report no conflicts of interest in this work.

\section{References}

1. Cheng J. The significance of expressing SOX2 in esophageal squamous cell carcinoma. World J Digestology. 2011;19:1698-1703. doi:10.11569/wcjd.v19.i16.1698

2. Raghoebir L, Bakker ERM, Mills JC, et al. SOX2 redirects the developmental fate of the intestinal epithelium toward a premature gastric phenotype. J Mol Cell Biol. 2012;4:377-385. doi:10.1093/jmcb/ mjs030

3. Ye F, Li Y, Hu Y, Zhou C, Hu Y, Chen H. Expression of Sox2 in human ovarian epithelial carcinoma. $J$ Cancer Res Clin Oncol. 2011;137:131-137. doi:10.1007/s00432-010-0867-y

4. Neumann J, Bahr F, Horst D, et al. SOX2 expression correlates with lymph-node metastases and distant spread in right-sided colon cancer. BMC Cancer. 2011;11:518. doi:10.1186/1471-2407-11-518

5. Kang J, Shakya A, Tantin D. Stem cells, stress, metabolism and cancer: a drama in two Octs. Trends Biochem Sci. 2009;34:491-499. doi:10.1016/j.tibs.2009.06.003

6. Zhang J, Li YL, Zhou CY, Hu YT, Chen HZ. Expression of octamer-4 in serous and mucinous ovarian carcinoma. $J$ Clin Pathol. 2010;63:879-883. doi:10.1136/jcp.2009.073593

7. Tsai LL, Hu F-W, Lee -S-S, et al. Oct4 mediates tumor initiating properties in oral squamous cell carcinomas through the regulation of epithelial-mesenchymal transition. PLoS One. 2014;9:e87207. doi:10.1371/journal.pone. 0087207

8. Cheng W. Incidence and death of malignant tumors in China in 2010. Chin Cancer. 2014;23:01-21.

9. Al-Hajj M, Clarke MF. Self-renewal and solid tumor stem cells. Oncogene. 2004;23:7274-7282. doi:10.1038/sj.onc.1207947

10. Croker AK, Goodale D, Chu J, et al. High aldehyde dehydrogenase and expression of cancer stem cell markers selects for breast cancer cells with enhanced malignant and metastatic ability. J Cell Mol Med. 2009;13:2236-2252. doi:10.1111/j.1582-4934.2008.00455.x
11. Bertrand J, Begaud-Grimaud G, Bessette B, Verdier M, Battu S, Jauberteau M-O. Cancer stem cells from human glioma cell line are resistant to Fas-induced apoptosis. Int $J$ Oncol. 2009;34:717-727.

12. Klarmann GJ, Hurt EM, Mathews LA, et al. Invasive prostate cancer cells are tumor initiating cells that have a stem cell-like genomic signature. Clin Exp Metastasis. 2009;26:433-446. doi:10.1007/s10585-009-9242-2

13. Taghizadeh R, Noh M, Huh YH, et al. CXCR6, a newly defined biomarker of tissue-specific stem cell asymmetric self-renewal, identifies more aggressive human melanoma cancer stem cells. PLoS One. 2010;5:e15183. doi:10.1371/journal.pone. 0015183

14. Chu P, Clanton DJ, Snipas TS, et al. Characterization of a subpopulation of colon cancer cells with stem cell-like properties. Int J Cancer. 2009;124:1312-1321. doi:10.1002/ijc.24061

15. Gumucio DL, Fagoonee S, Qiao XT, et al. Tissue stem cells and cancer stem cells: potential implications for gastric cancer. Panminerva Med. 2008;50:65-71.

16. Whittington N, Cunningham D, Le TK, De Maria D, Silva EM. Sox21 regulates the progression of neuronal differentiation in a dose-dependent manner. Dev Biol. 2015;397:237-247. doi:10.1016/ j.ydbio.2014.11.012

17. Kuroda T, Tada M, Kubota H, et al. Octamer and Sox elements are required for transcriptional cis regulation of Nanog gene expression. Mol Cell Biol. 2005;25:2475-2485. doi:10.1128/MCB.25.6.24752485.2005

18. Gangemi RM, Griffero F, Marubbi D, et al. SOX2 silencing in glioblastoma tumor-initiating cells causes stop of proliferation and loss of tumorigenicity. Stem Cells. 2009;27:40-48. doi:10.1634/stemcells.2008-0493

19. Wilbertz T, Wagner P, Petersen K, et al. SOX2 gene amplification and protein overexpression are associated with better outcome in squamous cell lung cancer. Mod Pathol. 2011;24:944-953. doi:10.1038/ modpathol.2011.49

20. Hussenet T, Dali S, Exinger J, et al. SOX2 is an oncogene activated by recurrent 3q26.3 amplifications in human lung squamous cell carcinomas. PLoS One. 2010;5:e8960. doi:10.1371/journal.pone.0008960

21. Lengerke $\mathrm{C}$, et al. Expression of the embryonic stem cell marker SOX2 in early-stage breast carcinoma. BMC Cancer. 2011;11,42. doi:10.1186/1471-2407-11-42.2011

22. Jiang WL, Zhang P-F, Li G-F, Dong J-H, Wang X-S, Wang -Y-Y. Oct-4is associated with gastric cancer progression and prognosis. Onco Targets Ther. 2016;9:517-522. doi:10.2147/OTT.S90031

23. Santagata S, Ligon KL, Hornick JL. Embryonic stem cell transcription factor signatures in the diagnosis of primary and metastatic germ cell tumors. Am J Surg Pathol. 2007;31:836-845. doi:10.1097/ PAS.0b013e31802e708a

24. Duinsbergen D, Eriksson M, Ac't Hoen P, Frisen J, Mikkers H. Induced pluripotency with endogenous and inducible genes. Exp Cell Res. 2008;314:3255-3263. doi:10.1016/j.yexcr.2008.06.024

25. Cheng L. Establishing a germ cell origin for metastatic tumors using OCT4 immunohistochemistry. Cancer. 2004;101:2006-2010. doi: $10.1002 /$ cncr.20566

26. Kim RJ, Nam JS. OCT4 expression enhances features of cancer stem cells in a mouse model of breast cancer. Lab Anim Res. 2011;27:147-152. doi:10.5625/lar.2011.27.2.147

27. Yuan F, Zhou W, Zou C, et al. Expression of Oct4 in HCC and modulation to wnt/beta-catenin and TGF-beta signal pathways. Mol Cell Biochem. 2010;343:155-162. doi:10.1007/s11010-0100509-3

28. Karoubi G, Gugger M, Schmid R, Dutly A. OCT4 expression in human non-small cell lung cancer: implications for therapeutic intervention. Interact Cardiovasc Thorac Surg. 2009;8:393-397. doi:10.1510/icvts.2008.193995

29. Saigusa S, Tanaka K, Toiyama Y, et al. Correlation of CD133, OCT4, and SOX2 in rectal cancer and their association with distant recurrence after chemoradiotherapy. Ann Surg Oncol. 2009;16:3488-3498. doi:10.1245/s10434-009-0617-z 
30. Takahashi K, Yamanaka S. Induction of pluripotent stem cells from mouse embryonic and adult fibroblast cultures by defined factors. Cell. 2006;126:663-676. doi:10.1016/j.cell.2006.07.024

31. Eggenschwiler R, Cantz T. Induced pluripotent stem cells generated without viral integration. Hepatology. 2009;49:1048-1049. doi:10.1002/ hep. 22827

32. Carette JE, et al. Generation of iPSCs from cultured human malignant cells. Blood. 2010;115:4039-4042. doi:10.1182/blood-2009-07-231845

33. Wernig M, Lengner CJ, Hanna J, et al. A drug-inducible transgenic system for direct reprogramming of multiple somatic cell types. Nat Biotechnol. 2008;26:916-924. doi:10.1038/nbt1483

34. Hanna J, Markoulaki S, Schorderet P, et al. Direct reprogramming of terminally differentiated mature B lymphocytes to pluripotency. Cell. 2008;133:250-264. doi:10.1016/j.cell.2008.03.028

35. Lin SL, Chang DC, Chang-Lin S, et al. Mir-302 reprograms human skin cancer cells into a pluripotent ES-cell-like state. RNA. 2008;14:2115-2124. doi:10.1261/rna.1162708

36. Miyoshi N, Ishii H, Nagai K-I, et al. Defined factors induce reprogramming of gastrointestinal cancer cells. Proc Natl Acad Sci U S A. 2010;107:40-45. doi:10.1073/pnas.0912407107

37. Tian T, Zhang Y, Wang S, Zhou J, Xu S. Sox2 enhances the tumorigenicity and chemoresistance of cancer stem-like cells derived from gastric cancer. J Biomed Res. 2012;26:336-345. doi:10.7555/JBR.26.20120045

38. Hutz K, Mejías-Luque R, Farsakova K, et al. The stem cell factor SOX2 regulates the tumorigenic potential in human gastric cancer cells. Carcinogenesis. 2014;35:942-950. doi:10.1093/carcin/ bgt410

39. Matsuoka J, Yashiro M, Sakurai K, et al. Role of the stemness factors sox2, oct3/4, and nanog in gastric carcinoma. J Surg Res. 2012;174:130-135. doi:10.1016/j.jss.2010.11.903
40. Singh SK, Clarke ID, Terasaki M, et al. Identification of a cancer stem cell in human brain tumors. Cancer Res. 2003;63:5821 -5828 .

41. Nichols J, Zevnik B, Anastassiadis K, et al. Formation of pluripotent stem cells in the mammalian embryo depends on the POU transcription factor Oct4. Cell. 1998;95:379-391.

42. Tai MH, Chang -C-C, Kiupel M, Webster JD, Olson LK, Trosko JE. Oct4 expression in adult human stem cells: evidence in support of the stem cell theory of carcinogenesis. Carcinogenesis. 2005;26:495-502. doi:10.1093/carcin/bgh321

43. Liu J, Wang L, Ma L, et al. Significantly increased expression of OCT4 and ABCG2 in spheroid body-forming cells of the human gastric cancer MKN-45 cell line. Oncol Lett. 2013;6:891-896. doi: $10.3892 / \mathrm{ol} .2013 .1506$

44. Liu J, Ma L, Xu J, et al. Spheroid body-forming cells in the human gastric cancer cell line MKN-45 possess cancer stem cell properties. Int J Oncol. 2013;42:453-459. doi:10.3892/ ijo.2012.1720

45. Chen Z, Xu W-R, Qian H, et al. Oct4, a novel marker for human gastric cancer. J Surg Oncol. 2009;99:414-419. doi:10.1002/jso.21270

46. Tapia, N., MacCarthy, C., Esch, D. et al. Dissecting the role of distinct OCT4-SOX2 heterodimer configurations in pluripotency. Sci Rep. 2015;5. ARTN 13533. doi:10.1038/srep13533

47. Wang ZW, Liu PD, Inuzuka H, Wei WY. Roles of F-box proteins in cancer. Nat Rev Cancer. 2014;14:233-247. doi:10.1038/ $\operatorname{nrc} 3700$

48. Boyer LA, Lee TI, Cole MF, et al. Core transcriptional regulatory circuitry in human embryonic stem cells. Cell. 2005;122:947-956. doi:10.1016/j.cell.2005.08.020
OncoTargets and Therapy

\section{Publish your work in this journal}

OncoTargets and Therapy is an international, peer-reviewed, open access journal focusing on the pathological basis of all cancers, potential targets for therapy and treatment protocols employed to improve the management of cancer patients. The journal also focuses on the impact of management programs and new therapeutic

\section{Dovepress}

agents and protocols on patient perspectives such as quality of life, adherence and satisfaction. The manuscript management system is completely online and includes a very quick and fair peer-review system, which is all easy to use. Visit http://www.dovepress.com testimonials.php to read real quotes from published authors. 